\title{
Sorption, Solubility and Residual Monomers of a Dental Adhesive Cured by Different Light-Curing Units
}

\author{
Francine do Couto Lima MOREIRA ${ }^{1}$ \\ Nelson Roberto ANTONIOSI FILHO ${ }^{2}$ \\ João Batista de SOUZA ${ }^{1}$ \\ Lawrence Gonzaga LOPES ${ }^{1}$ \\ ${ }^{1}$ Department of Prevention and Oral Rehabilitation, Dental School, Federal University of Goiás, Goiânia, GO, Brazil \\ ${ }^{2}$ Chemistry Institute, Federal University of Goiás, Goiânia, GO, Brazil
}

\begin{abstract}
The aim of this study was to assess polymerization ability of three light-curing units by evaluating the influence of the light source, curing regimen and permeant (water or ethanol) on sorption, solubility and amount of residual monomers of a dental adhesive. Specimens of Adper Single Bond 2 were fabricated using a stainless steel circular matrix ( $8 \mathrm{~mm}$ x $1 \mathrm{~mm}$ ). One quartz-tungsten-halogen (QTH) lamp and two light-emitting diode (LED) device at three different curing regimes (L1 = $12 \mathrm{~J}$; L2 $=24 \mathrm{~J}$; L3 = $24 \mathrm{~J}$ ) were used to cure the specimens. Specimens were stored in two types of permeants - deionized water or $75 \%$ ethanol - for two storage times (G1 $=7$ days; $\mathrm{G} 2=30$ days). The specimens underwent water sorption and solubility tests, according to ISO 4049:2000 standard. After storage, residual monomers were identified and quantified by high performance liquid chromatography (HPLC). For sorption, L1 showed the highest values and QTH, the lowest. For solubility, in ethanol-stored groups, L1 had also the highest values, and QTH, the lowest, and findings were significantly different from the other curing regimens. L1 leached significantly more monomers than the others, and QTH had the lowest results. In conclusion, the type of light source, the curing regimen and the permeant affected sorption, solubility and amount of residual monomers of the adhesive under study.
\end{abstract}

Key Words: adhesive, dental materials, HPLC, solubility, sorption.

\section{INTRODUCTION}

Adhesive systems should provide adequate marginal seal and retention of resin composite restorations to dental structures, when used appropriately. Significant technological advances have been made to obtain effective bonding of resin-based materials to dentin and enamel. As water is essential to maintain collagen fibrils expanded after demineralization, adhesives should be compatible with wet dentin substrates (1).

Currently, most adhesives are simplified systems. Both etch-and-rinse and self-etching systems are user-friendly, which reduces the number of steps of the bonding protocol (1). These systems are based on hydrophilic resin monomers, usually 2-hydroxyethyl methacrylate (HEMA), associated or not with hydrophobic dimethacrylates, as bisphenol A diglycidyl methacrylate (Bis-GMA) (2). However, several factors affect the properties of adhesive systems. The degree of monomer-polymer conversion achieved with lightcuring, when incomplete, results in residual monomers (3), which may contribute to bonding agent degradation that can irritate the dental pulp (4).

Chemical degradation is usually caused by oxidation and hydrolysis, which are processes that require the presence of water (3). Adhesive materials are affected by sorption and solubility because of their composition (5).

When a solvent enters the polymer network, it causes an expansion of the structure, facilitates extraction of monomers that did not react and promotes the dissolution of linear polymer chains (3). This expansion is facilitated when the density of crosslinks is low. Thus, polymers with a high density of crosslinks are more

Correspondence: Prof. Dr. Lawrence G. Lopes, Departamento de Prevenção e Reabilitação Oral, Faculdade de Odontologia, Setor Universitário, UFG. Praça Universitária, S/N, 74605220 Goiânia, GO, Brasil. Tel: +55-62-3209-6050. Fax: +55-62-35210-1882. e-mail: drlawrenceg@yahoo.com.br 
resistant to degradation due to the greater limitation of space and possible paths for the diffusion of permeants in the polymer structure (3). Such water sorption may contribute to the failure of adhesive-dentin bonds (6).

The degree of conversion affects the physical properties and chemical stability of adhesive materials directly (7). The higher the conversion degree, the better the surface properties, such as hardness, modulus of elasticity, resistance to fracture and diametral tensile strength. However, these mechanical properties depend on the type of polymeric chain and density of crosslinks formed during the polymerization process (8).

In this context, the light-curing unit is essential for the success of adhesive restorations. Appliance variables, such as adequate light intensity, correct wavelength and energy density (power density x exposure time), are essential to achieve proper depth of cure (9). Light from the curing source must adequately polymerize deeper composite regions and have a wavelength to initiate photo-curing of methacrylate groups and produce a highly cross-linked structure (10). However, monomer conversion is not complete in the polymerization reaction, and unreacted monomers are released from the polymer to the oral environment (7). Identification and measurement of the amount of residual monomers eluted from polymers is a good manner to evaluate polymer quality. High performance liquid chromatography (HPLC) is the preferred method for this (7).

Different types of light-curing units have been developed for the curing of light-activated restorative materials: conventional quartz tungsten halogen $(\mathrm{QTH})$ lights $(10,11)$, plasma arc curing (PAC) (11), argon laser and, more recently, a new technology using lightemitting diode (LED) (12). These devices emit blue light in the spectrum of absorption of camphorquinone, which is the photoinitiator found in most resinous materials (12).

LED sources seem to be a promising technology for polymerization of dental resin materials. However, its application in composite curing remains controversial.

This study assessed the polymerization ability of three light-curing units by evaluating the influence of the light source, curing regimen and permeant (water and ethanol) on sorption, solubility and amount of residual monomers of a dental adhesive. The null hypotheses were: (1) the type of light source and curing regimen does not affect sorption, solubility and amount of eluted residual monomers; (2) different permeants (water and $75 \%$ ethanol) have similar effects on sorption, solubility and amount of eluted residual monomers; (3) different storage times do not affect sorption, solubility and amount of eluted residual monomers.

\section{MATERIAL AND METHODS}

Adper Single Bond 2 (SB; 3M ESPE, St Paul, MN, USA) was the adhesive system used. Its manufacturers, classification and main contents are shown in Table 1.

\section{Preparation of Specimens}

This study was performed in compliance with ISO 4049:2000 standard specifications (13), except for specimen dimensions.

For specimen preparation, SB was directly dispensed drop-by-drop into a stainless steel matrix ( $8 \mathrm{~mm}$ in diameter; $1 \mathrm{~mm}$ thick) until it was filled completely. A polyester strip was placed over the

Table 1. Experimental design, light-curing units' and adhesive system characteristics.

\begin{tabular}{|c|c|c|c|c|c|c|}
\hline $\begin{array}{l}\text { Light-curing } \\
\text { units }\end{array}$ & $\begin{array}{l}\text { Light } \\
\text { sources }\end{array}$ & $\begin{array}{l}\text { Exposure } \\
\text { time (s) }\end{array}$ & $\begin{array}{l}\text { Power density } \\
\quad\left(\mathrm{mW} / \mathrm{cm}^{2}\right)\end{array}$ & $\begin{array}{l}\text { Energy density } \\
\qquad\left(\mathrm{J} / \mathrm{cm}^{2}\right)\end{array}$ & Manufacturer & Adhesive system \\
\hline Ultralux & $\begin{array}{l}\text { Halogen } \\
\text { (QTH) }\end{array}$ & 40 & 600 & 24 & $\begin{array}{c}\text { Dabi Atlante, } \\
\text { Ribeirão Preto, SP, } \\
\text { Brazil }\end{array}$ & \multirow{4}{*}{$\begin{array}{c}\text { Adper Single Bond } 2 \\
\text { Batch number: 8RT } \\
\text { (2011/06) } \\
\text { Composition: } \\
\text { water; ethanol; } \\
\text { Bis-GMA; HEMA; } \\
\text { camphorquinone; } \\
\text { dimethacrylates. }\end{array}$} \\
\hline $\begin{array}{l}\text { Elipar } \\
\text { Freelight } 2\end{array}$ & LED (L1) & 10 & 1200 & 12 & $\begin{array}{c}\text { 3M ESPE, St Paul, } \\
\text { MN, USA }\end{array}$ & \\
\hline $\begin{array}{l}\text { Elipar } \\
\text { FreeLight } 2\end{array}$ & LED (L2) & 20 & 1200 & 24 & $\begin{array}{c}\text { 3M ESPE, St Paul, } \\
\text { MN, USA }\end{array}$ & \\
\hline Emitter & LED (L3) & 40 & 600 & 24 & $\begin{array}{c}\text { Schuster, Santa } \\
\text { Maria, RS, Brazil }\end{array}$ & \\
\hline
\end{tabular}


adhesive and covered with a glass slide. SB was cured using three light-curing units, one QTH lamp (QTH) and two LED devices, whose specifications are shown in Table 1. A continuous polymerization technique was used. The type of light source, power density and exposure time varied to achieve the same energy density with the three devices. Five specimens were fabricated for each subgroup (13) (Fig. 1). Light irradiance for each cure mode was checked before use with the inbuilt radiometer to ensure consistency of light output. The curing tip was placed directly on glass slide which guaranteed the maintenance of the same distance of irradiation for all specimens. The polymerized specimens were removed from the matrix and excesses were removed with a \#15 scalpel blade.

\section{Sorption and Solubility Test}

The specimens were placed in open glass bottles, which were placed in desiccators containing freshly dried white silica $\left(\operatorname{Vetec}^{\circledR}\right.$, batch 0506198) and kept at $37 \pm 1^{\circ} \mathrm{C}$ inside a vacuum oven for $22 \mathrm{~h}$ (LF Equipment - Model 440 D). After that, the desiccators containing the specimens were removed from the oven and left on a bench for $2 \mathrm{~h}$ at a temperature of $23^{\circ} \pm 1^{\circ} \mathrm{C}$, which completed a 24-h cycle. The discs were weighed daily using an analytical balance (AB204-S, Mettler Toledo, São Paulo, SP, Brazil; accuracy to $0.01 \mathrm{mg}$ ) to record

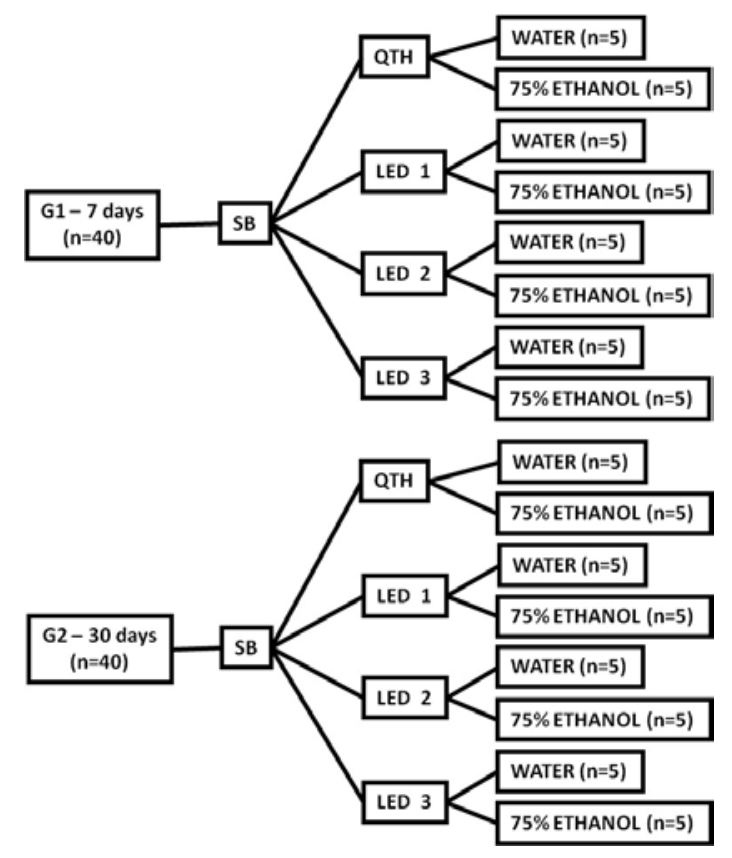

Figure 1. Diagram of specimens' distribution in the groups. 24-h weighing cycles. The complete cycle was repeated until a constant mass (M1) was obtained, i.e., until the mass loss for each specimen was not more than 0.1 mg per 24-h cycle. Thereafter, the specimens were carefully placed back in their labeled bottles, and 15 $\mathrm{mL}$ of permeant, either deionized water (W) or $75 \%$ ethanol (E), were added using manual pipettes (one for each permeant). The bottles were sealed, brought back into the oven and kept at a $37^{\circ} \pm 1^{\circ} \mathrm{C}$ for 7 (G1) or 30 (G2) days.

After these periods, all the bottles were removed from the oven and kept at room temperature $\left(23^{\circ} \pm 1^{\circ} \mathrm{C}\right)$ for $2 \mathrm{~h}$. The specimens were removed from the bottles, dried with absorbent paper for $15 \mathrm{~s}$ and left in a sterile bucket for $1 \mathrm{~min}$. They were then weighed again to obtain M2. After weighting, the specimens were reconditioned in the desiccators until they reached a constant weight (M3) using the cycle describe for M1.

The values for water sorption (Wsp) and solubility (Wsl) in micrograms per cubic millimeter were calculated using the following equations: Wsp=(M2$\mathrm{M} 3) / \mathrm{V} ; \mathrm{Ws} 1=(\mathrm{M} 1-\mathrm{M} 3) / \mathrm{V}$. Data were analyzed by two-way ANOVA and the Tukey's test for multiple comparisons $(\alpha=0.05)$.

\section{HPLC Analysis}

Five milliliters of permeant samples were collected to analyze the presence and amount of residual non-reactive monomers that were released from the specimens after each storage period. The analysis was made using high performance liquid chromatography (HPLC) on a system (Shimadzu ${ }^{\circledR}$, software Class-VP 6.14) equipped with a $300 \times 3.9 \mathrm{~mm}$ column packed with $4 \mu \mathrm{m} \mathrm{C}-18$ silica (Nova-Pak ${ }^{\circledR}$ C-18; Waters, Darmstadt, Ireland) under the following conditions: gradient elution mode - for the first $20 \mathrm{~min}$ a linear gradient solvent of $100 \%$ acetonitrile to $50 \%$ acetonitrile in water, then 22 $\mathrm{min}$ in $50 \%$ acetonitrile/water; $0.4 \mathrm{~mL} / \mathrm{min}$ flow rate; detection at $205 \mathrm{~nm} ; 20 \mu \mathrm{L}$ sampling loop, $25^{\circ} \mathrm{C} \pm 1^{\circ} \mathrm{C}$ temperature. The column was calibrated with known concentrations of monomers. Bis-GMA (Freeman Chemical Co., Port Washington, WI, USA) and HEMA (Freeman Chemical Co.) solutions of each monomer in ethanol/water (75:25), at concentrations of $5 \mathrm{mg} . \mathrm{L}^{-1}, 10$ mg. $\mathrm{L}^{-1}, 20 \mathrm{mg} . \mathrm{L}^{-1}, 50 \mathrm{mg} . \mathrm{L}^{-1}, 100 \mathrm{mg} . \mathrm{L}^{-1}$ and $200 \mathrm{mg} . \mathrm{L}^{-1}$. The linear fittings of Bis-GMA and HEMA calibration curves were used to calculate the concentration of each monomer in the extracts, based on the area of the 
chromatographic peaks at the corresponding retention times (RT). The HPLC analysis was performed using the extract of 5 samples from each subgroup. The results for the amount of eluted monomer per subgroup were statistically compared with ANOVA and the Tukey's test for multiple comparisons $(\alpha=0.05)$.

\section{RESULTS}

There were significant differences $(p<0.05)$ for water sorption, solubility and amount of residual monomers values. Table 2 presents the results for water sorption (Wsp). No significant differences $(\mathrm{p}>0.05)$ were observed between QTH, L2 and L3 values for water-stored specimens, and L1 had the lowest values $(p<0.05)$. The values of sorption for $75 \%$ ethanol were higher than for water. Therefore, there were no significant differences ( $p>0.05$ ) between L 2 and L3 in the ethanol group. However, L1 showed the highest significant values, and $\mathrm{QTH}$, the lowest $(\mathrm{p}<0.05)$. These findings occurred both in G1 and G2.

The results for solubility (Wsl) are shown in Table 3. For G1 and in water permeant, there were no significant differences between QTH, L1 and L2 ( $>0.05)$. L3 had significantly lower solubility values than L1 $(\mathrm{p}<0.05)$, but similar to QTH and L2 $(p>0.05)$. For $G 2$ and water permeant, there were no significant differences ( $p>0.05$ ) among L1, L2 and L3. QTH generated significantly lower $(\mathrm{p}<0.05)$ solubility values than L1 and L2, but statistically similar to L3 $(\mathrm{p}>0.05)$. In both ethanol groups (G1 and G2), L1 had the highest values, and QTH, the lowest, and findings were significantly different $(\mathrm{p}<0.05)$ from the other

Table 2. Means ( \pm s.d.) of water sorption (Wsp) in $\mu \mathrm{g} / \mathrm{mm}^{3}$.

\begin{tabular}{lccccc}
\hline \multirow{2}{*}{ Light source } & \multicolumn{2}{c}{ G1 } & & \multicolumn{2}{c}{$\mathrm{G} 2$} \\
\cline { 2 - 3 } \cline { 5 - 6 } & W (s.d.) & E (s.d.) & & W (s.d.) & E (s.d.) \\
\hline \multirow{2}{*}{ QTH } & 193.82 & 230.04 & & 181.52 & 307.02 \\
& $(17.89)^{\mathrm{A}}$ & $(29.65)^{\mathrm{C}}$ & & $(9.05)^{\mathrm{A}}$ & $(12.73)^{\mathrm{C}}$ \\
L1 & 143.28 & 353.50 & & 142.91 & 432.72 \\
& $(6.28)^{\mathrm{B}}$ & $(24.23)^{\mathrm{A}}$ & & $(14.31)^{\mathrm{B}}$ & $(22.14)^{\mathrm{A}}$ \\
L2 & 195.42 & 290.20 & & 195.06 & 353.9 \\
& $(7.09)^{\mathrm{A}}$ & $(38.94)^{\mathrm{B}}$ & & $(19.70)^{\mathrm{A}}$ & $(9.27)^{\mathrm{B}}$ \\
L3 & 176.32 & 303.00 & & 193.86 & 334.39 \\
& $(23.26)^{\mathrm{A}}$ & $(22.51)^{\mathrm{B}}$ & & $(6.68)^{\mathrm{A}}$ & $(13.28)^{\mathrm{B}}$ \\
\hline
\end{tabular}

Same superscript letters in columns indicate no statistically significant difference (Tukey's test; $\mathrm{p}=0.05$ ). curing regimes. There were no significant differences ( $p>0.05)$ between L2 and L3.

Figure 2 (chromatogram) shows the compounds eluted from a water-stored sample where HEMArepresents the highest peak. Figure 3 shows in the chromatogram the compounds eluted from an ethanol-stored sample, where Bis-GMA represents the highest peak.

Tables 4 and 5 show the mean amounts of HEMA and Bis-GMA eluted from G1 and G2, respectively. Bis-GMA was not detected in water samples after either storage times.

For G1, regardless of permeant agent, the specimens cured with L1 leached significantly more monomers (HEMA and Bis-GMA) than QTH, L2 and L3 $(p<0.05)$. In water extraction, there was a statistically significant increase in amount of HEMA, and QTH $<$ $\mathrm{L} 3<\mathrm{L} 2<\mathrm{L} 1(\mathrm{p}<0.05)$. The analysis of ethanol samples did not reveal any significant differences $(p>0.05)$ in the Bis-GMA amount among QTH, L2 and L3. For HEMA, QTH had the lowest values, and the differences were significant $(p<0.05)$. As reported in G1, L1 leached significantly more monomers than QTH, L2 and L3 in $\mathrm{G} 2(\mathrm{p}<0.05)$. No significant differences $(\mathrm{p}>0.05)$ were found between L2 and L3 for amount of monomers (HEMA and Bis-GMA) in both permeants, and QTH showed the lowest results $(p<0.05)$.

Based on the findings of this study, the first two anticipated null hypothesis were partially rejected, and the third was almost completely accepted.

\section{DISCUSSION}

The hydrophilic nature of a polymer is largely

Table 3. Means ( \pm s.d.) of solubility (Wsl) in $\mu \mathrm{g} / \mathrm{mm}^{3}$.

\begin{tabular}{cccccc}
\hline \multirow{2}{*}{ Light source } & \multicolumn{2}{c}{$\mathrm{G} 1$} & & \multicolumn{2}{c}{$\mathrm{G} 2$} \\
\cline { 2 - 3 } \cline { 5 - 6 } & W (s.d.) & E (s.d.) & & W (s.d.) & E (s.d.) \\
\hline \multirow{2}{*}{ QTH } & 81.18 & 40.98 & & 64.48 & 40.3 \\
& $(6.51)^{\mathrm{A}, \mathrm{B}}$ & $(4.10)^{\mathrm{C}}$ & & $(5.55)^{\mathrm{B}}$ & $(14.48)^{\mathrm{C}}$ \\
L1 & 88.76 & 157.6 & & 80.81 & 150.87 \\
& $(2.26)^{\mathrm{A}}$ & $(12.39)^{\mathrm{A}}$ & & $(10.49)^{\mathrm{A}}$ & $(8.01)^{\mathrm{A}}$ \\
L2 & 84.78 & 57.7 & & 78.42 & 67.27 \\
& $(1.75)^{\mathrm{A}, \mathrm{B}}$ & $(12.88)^{\mathrm{B}}$ & & $(8.86)^{\mathrm{A}}$ & $(11.72)^{\mathrm{B}}$ \\
L3 & 74.02 & 65.15 & & 76.43 & 65.18 \\
& $(6.66)^{\mathrm{B}}$ & $(8.01)^{\mathrm{B}}$ & & $(5.38)^{\mathrm{A}, \mathrm{B}}$ & $(9.38)^{\mathrm{B}}$ \\
\hline
\end{tabular}

Same superscript letters in columns indicate no statistically significant difference (Tukey's test; $\mathrm{p}=0.05$ ). 
a function of the chemistry of its monomers and its polymerization linkages (2). Examinations of the most common monomers in dental adhesives (HEMA, BisGMA) showed that they form polymers with carbon and oxygen backbones. The presence of hydroxyl, carboxyl and phosphate groups in monomers and their resultant polymers make them more hydrophilic and, supposedly, more likely to undergo water sorption than resin composites (4).

G2 was designed for evaluations for more than 1 week. Specimens were stored for longer times to reach saturation, which is in accordance with findings by Örtengren et al. (14), who reported that most composites in their study reached saturation within 7-60 days. However, as dental adhesives absorb more permeant amounts than resin composites, G2 was designed for

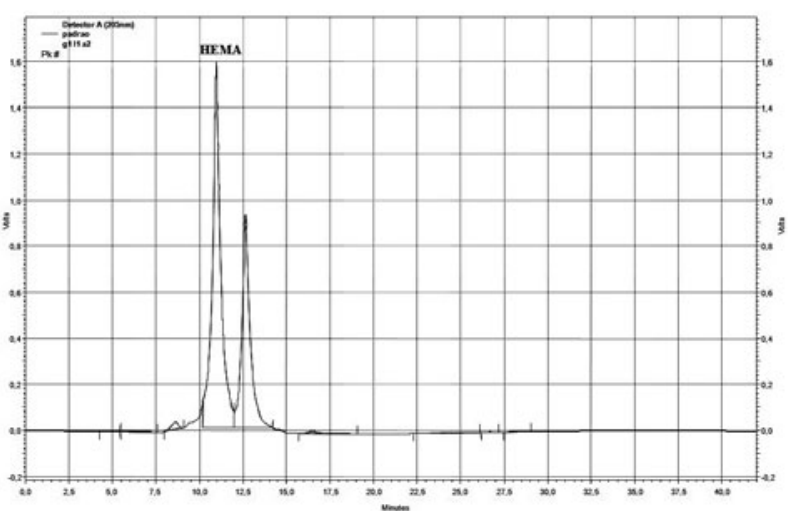

Figure 2. Chromatogram of a water-stored sample.

Table 4. Means ( \pm s.d.) of amount of monomers eluted from G1 specimens in $\mathrm{mg} \cdot \mathrm{L}^{-1}$.

\begin{tabular}{|c|c|c|c|c|}
\hline \multirow{2}{*}{$\begin{array}{l}\text { Light } \\
\text { sources }\end{array}$} & \multicolumn{2}{|c|}{ Water } & \multicolumn{2}{|c|}{ Ethanol } \\
\hline & $\begin{array}{c}\text { Bis-GMA } \\
\text { (s.d.) }\end{array}$ & $\begin{array}{c}\text { HEMA } \\
\text { (s.d.) }\end{array}$ & $\begin{array}{l}\text { Bis-GMA } \\
\text { (s.d.) }\end{array}$ & $\begin{array}{c}\text { HEMA } \\
\text { (s.d.) }\end{array}$ \\
\hline QTH & $\begin{array}{c}\text { No } \\
\text { detectable }\end{array}$ & $\begin{array}{c}0.83 \\
(1.99)^{\mathrm{D}}\end{array}$ & $\begin{array}{c}16.60 \\
(3.05)^{\mathrm{B}}\end{array}$ & $\begin{array}{c}8.71 \\
(3.06)^{\mathrm{C}}\end{array}$ \\
\hline L1 & $\begin{array}{c}\text { No } \\
\text { detectable }\end{array}$ & $\begin{array}{c}99.00 \\
(33.45)^{\mathrm{A}}\end{array}$ & $\begin{array}{c}121.76 \\
(18.56)^{\mathrm{A}}\end{array}$ & $\begin{array}{c}105.81 \\
(45.15)^{\mathrm{A}}\end{array}$ \\
\hline L2 & $\begin{array}{c}\text { No } \\
\text { detectable }\end{array}$ & $\begin{array}{c}34.50 \\
(3.81)^{\mathrm{B}}\end{array}$ & $\begin{array}{c}12.80 \\
(11.40)^{\mathrm{B}}\end{array}$ & $\begin{array}{c}27.87 \\
(10.66)^{\mathrm{B}}\end{array}$ \\
\hline L3 & $\begin{array}{c}\text { No } \\
\text { detectable }\end{array}$ & $\begin{array}{c}14.28 \\
(4.98)^{\mathrm{C}}\end{array}$ & $\begin{array}{c}9.62 \\
(7.08)^{\mathrm{B}}\end{array}$ & $\begin{array}{c}24.15 \\
(6.54)^{\mathrm{B}}\end{array}$ \\
\hline
\end{tabular}

Same superscript letters in columns indicate no statistically significant difference (Tukey's test; $\mathrm{p}=0.05$ ).
30 days in this study.

Chromatography is the preferred method to identify and quantify residual monomers released from dental polymers (14). Detection using gas chromatography (GC) is very fast, and GC has often been used to detect low molecular weight chemicals, such as HEMA(15). However, the analysis of large components, soluble and non-volatile reactive compounds such as BisGMA, should be conducted with HPLC (7). According to the manufacturer's information, HEMA and Bis-GMA are the main monomers in SB composition (Table 1); therefore, elution analysis was conducted using HPLC to detect both in this study.

The amount of solvent uptake by the polymer is determined by differences in solubility parameters between the polymer and the permeant; the greatest

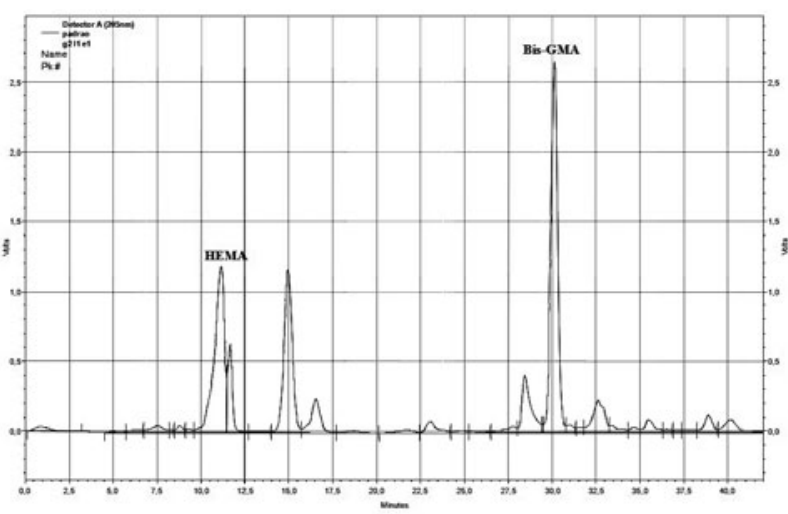

Figure 3. Chromatogram of an ethanol-stored sample.

Table 5. Means ( \pm s.d.) of amount of monomers eluted from G2 specimens in mg. $\mathrm{L}^{-1}$.

\begin{tabular}{lccccc}
\hline \multirow{2}{*}{$\begin{array}{l}\text { Light } \\
\text { sources }\end{array}$} & \multicolumn{2}{c}{ Water } & & \multicolumn{2}{c}{ Ethanol } \\
\cline { 2 - 3 } \cline { 5 - 6 } & $\begin{array}{c}\text { Bis-GMA } \\
\text { (s.d.) }\end{array}$ & $\begin{array}{c}\text { HEMA } \\
(\text { s.d. })\end{array}$ & & $\begin{array}{c}\text { Bis-GMA } \\
\text { (s.d. })\end{array}$ & $\begin{array}{c}\text { HEMA } \\
\text { (s.d.) }\end{array}$ \\
\cline { 2 - 3 } QTH & No & 1.59 & & 11.61 & 2.66 \\
& detectable & $(0.74)^{\mathrm{C}}$ & & $(2.35)^{\mathrm{C}}$ & $(3.16)^{\mathrm{C}}$ \\
L1 & No & 98.61 & & 129.28 & 122.36 \\
& detectable & $(20.15)^{\mathrm{A}}$ & & $(2.38)^{\mathrm{A}}$ & $(7.46)^{\mathrm{A}}$ \\
L2 & No & 28.16 & & 39.72 & 32.30 \\
& detectable & $(6.64)^{\mathrm{B}}$ & & $(4.21)^{\mathrm{B}}$ & $(8.50)^{\mathrm{B}}$ \\
& No & 31.22 & & 40.71 & 36.76 \\
L3 & detectable & $(2.07)^{\mathrm{B}}$ & & $(4.40)^{\mathrm{B}}$ & $(5.61)^{\mathrm{B}}$ \\
\hline
\end{tabular}

Same superscript letters in columns indicate no statistically significant difference (Tukey's test; $\mathrm{p}=0.05$ ). 
uptake is obtained when this difference is small (3). Ferracane (3) suggested that intraoral fluids are probably some of the most aggressive organic solvents. According to the USFDA(16), the use of $75 \%$ ethanol-water solution as a food/oral simulating liquid is clinically relevant. Moreover, and according to ISO specifications, distilled water is a solvent for resin-based filling materials (13) and simulates the wet intraoral environment where there is saliva and water. Therefore, water and $75 \%$ ethanol were also used in this study.

The type of light source used to activate polymerization may also lead to differences in water sorption and solubility of adhesive systems (5). Dental adhesives systems present an increased level of polymerization after prolonged light-curing times. The rate of resin elution changes with the increase of curing time, which indicates that, as crosslinking proceeds, the morphology of the polymer network also changes and either slows down or enhances the elution process (8).

Among the subgroups of in this study, L1 (12 J) had the lowest energy density and the highest sorption values, solubility and amount of monomers eluted were found when compared with the other curing regimes. L1 used the exposure time recommended by the manufacturer: " 10 s using a curing-light unit of the same manufacturer of the material". However, Rueggeberg et al. (17) found that exposure times recommended by manufacturers are not reliable indicators of optimal composite performance. Moreover, curing quickly at high intensity may produce more starter radicals and shorter (linear) polymer chains than low intensity curing, which results in low crosslink density. This facilitates expansion of the polymeric structure and extraction of monomers, and leads to the dissolution of linear polymer chains (3).

In contrast, $\mathrm{L} 1$ had the lowest values for sorption only when specimens were stored in water. Polymer has a very low cross-link density, and the expansion caused by water penetration in the polymer chain by sorption (3) may have led not only the elution of residual monomers, but also to the degradation of the polymer chain, which resulted in mass loss.

No significant differences were found in any parameters between LED units used for adhesive photoactivation at an energy density of $24 \mathrm{~J}$ (L2 and L3). However, LED groups had higher amounts of residual eluted monomers than QTH in the subgroups where $75 \%$ ethanol was used as permeant. The LED curing units promoted lower degree of conversion than the QTH curing unit, as observed by Arrais (18). This means that LED curing light might have generated fewer crosslinks in the polymer. This may be confirmed by the fact that the QTH unit generates more heat, which may speed up polymer chain induction in composite resins, because molecules may have greater mobility by heating, and more monomers may react before curing ends (8). Moreover, polymerization does not stop right after the photoactivation period, and heat contributes for this post-activation polymerization. The lowest amounts of residual monomers in the QTH group may also be explained by the absorbance of camphorquinone. Although the maximum absorbance of camphorquinone takes place at $468 \mathrm{~nm}$, its absorption band (380-510 nm) coincides with the light band emitted by QTH lamps, and more camphorquinone molecules are activated (19).

Sideridou et al. (4) reported that solubility measurements in dental biomaterials reflect leachability by the water amount of unreacted monomers. However, as it can be seen in Figures 2 and 3, other adhesive compounds are leached from the polymer network, so solubility values represent all leached compounds. Thus, in order to quantify unreacted monomers, they should be identified separately from the other compounds which explain the differences between solubility values and amount of monomers in water subgroups.

HEMA flows more easily into water than BisGMA because of its lower molecular weight and its hydrophilic chemical structure, which has a hydroxyl radical with high affinity to hydrogen bonding (15). The high-molecular-weight Bis-GMA is a difunctional monomer that has a large molecular size and a chemical structure that provides high viscosity, low volatility, low polymerization shrinkage, and rapid hardening, and which, hence, produces stronger and stiffer resins (15). Bis-GMA was not detected by HPLC in subgroups stored in water after either storage times. Even in G2 specimens, which were stored for 30 days in water, most residual Bis-GMA monomers remained in the set adhesive (4). However, a great amount of dimethacrylates was found in ethanol both in G1 and G2, which may be explained by the fact that $75 \%$ ethanol has a solubility parameter which matches that of Bis-GMA. Therefore, it is the permeant of choice to simulate accelerated ageing of restorations (16).

A larger amount of unreacted monomers was found in this experiment than in other studies $(4,9)$ that quantified residual eluted monomers used resin composites as test material, and resins contain only 
$25 \%$ of organic matrix in its composition. Sideridou et al. (4) reported that a decrease in sorption, solubility and leachability of compounds occurs with increasing filler loading. Conversely, dental adhesives contain high percentages of organic compounds (monomers) in their composition, which would make them more likely to undergo sorption, solubility and elution.

No significance differences were found in the amounts of residual monomers between G1 and G2 (7 or 30 days). This result is in agreement with the findings of a previous study (20) in which $75 \%$ of the elutable species were extracted within a few hours, and that $95 \%$ are extracted within $48 \mathrm{~h}$.

In conclusion, light source, curing regimen and permeant (water and ethanol) affected sorption, solubility and amount of residual monomers of the adhesive under study.

\section{ACKNOWLEDGMENTS}

The authors would like to thank 3M ESPE for supplying materials, the Brazilian Ministry of Education for research funding, and LAMES/IQ-UFG (FUNAPE/ FINEP) for research support.

\section{RESUMO}

O objetivo deste estudo foi avaliar a capacidade de polimerização de três unidades fotopolimerizadoras por meio da análise da influência das fontes de luz, regimes de cura (QTH, L1, L2 e L3) e diferentes permeantes (água e etanol) na sorção, solubilidade e quantidade de monômeros residuais de um adesivo dentário. Espécimes de Adper ${ }^{\mathrm{TM}}$ Single Bond 2 foram feitos utilizando uma matriz circular de aço inoxidável $(8 \mathrm{~mm} \times 1 \mathrm{~mm})$. Três fontes de luz, uma a base de luz halógena (QTH) e duas a base de diodos emissores de luz (LED), em três diferentes regimes de cura (L1 = $12 \mathrm{~J} ; \mathrm{L} 2=24 \mathrm{~J} ; \mathrm{L} 3=24 \mathrm{~J}$ ) foram usados para fotoativar os espécimes. Os espécimes foram armazenados em dois tipos de permeantes (água deionizada ou etanol a 75\%), por dois diferentes períodos de armazenamento ( $\mathrm{G} 1=7$ dias; $\mathrm{G} 2=30$ dias). Os espécimes foram submetidos a testes de sorção e solubilidade de acordo com a ISO 4049:2000. Após o período de armazenamento, os monômeros residuais foram identificados e quantificados por cromatografia líquida de alta eficiência (HPLC). Para sorção, L1 apresentou os maiores valores significantes e QTH os menores. Para solubilidade, nos grupos do etanol, L1 apresentou os maiores valores e QTH os menores e os achados foram estatisticamente diferentes dos outros regimes de cura. L1 extraiu significantemente mais monômeros do que os outros regimes e QTH teve os menores resultados. As fontes de luz, os regimes de polimerização e os diferentes permeantes influenciaram na sorção, solubilidade e quantidade de monômeros residuais extraídos do adesivo em estudo.

\section{REFERENCES}

1. Tyas MJ, Burrow MF. Adhesive restorative materials: a review.
Aust Dent J 2004;49:112-121.

2. Malacarne J, Carvalho RM, de Goes MF, Svizero N, Pashley DH, Tay FR. Water sorption/solubility of dental adhesive resins. Dent Mater 2006;22:973-980.

3. Ferracane JL. Hygroscopic and hydrolytic effects in dental polymer networks. Dent Mater 2006;22:211-222.

4. Sideridou I, Achilias DS, Spyroudi C, Karabela M. Water sorption characteristics of light-cured dental resins and composites based on Bis-EMA/PCDMA. Biomater 2004;25:367-376.

5. Fabre HSC, Fabre S, Cefaly DFG, Carrilho MRO, Garcia FCP, Wang L. Water sorption and solubility of dentin bonding agents light-cured with different light sources. J Dent 2007;35:253-258.

6. Danphal P, Yiu CK, King NM, Tay FR, Hiraishi N. Effect of temperature on water sorption and solubility of dental adhesive resins. J Dent 2009;37:122-132.

7. Rueggeberg FA, Craig RG. Correlation of parameters used to estimate monomer conversion in a light-cured composite. J Dent Res 1988:67:932-937.

8. Yap AU, Soh MS, Han TT, Siow KS. Influence of curing lights and modes on cross-link density of dental composites. Oper Dent 2004;29:410-415.

9. Pulgar R, Olea-Serrano MF, Novillo-Fertrell, Rivas A, Pazos P, Pedraza V, et al.. Determination of Bisphenol A and related aromatic compounds released from Bis-GMA-based composites and sealants by high performance liquid chromatography. Environ Health Perspect 2000;108:21-27.

10. Obici AC, Sinhoreti MA, de Goes MF, Consani S, Sobrinho LC. Effect of the photo-activation method on polymerization shrinkage of restorative composites. Oper Dent 2002;27:192-198.

11. Tarle, Z. Composite conversion and temperature rise using a conventional, plasma arc, and an experimental blue LED curing unit. J Oral Rehabil 2002;29:662-667.

12. Kurachi C, Tuboy AM, Magalhães DV, Bagnato VS. Hardness evaluation of a dental composite polymerized with experimental LED-based devices. Dent Mater 2001;17:309-315.

13. International Organization for Standardization. ISO4049: Dentistry polymer - based filling, restorative and luting materials. Switzerland, 2000.

14. Örtengren U, Wellendorf H, Harlosson S, Ruyter IE. Water sorption and solubility of dental composites and identification of monomers released in an aqueous environment. J Oral Rehabil. 2001;28:1106-1115.

15. Tanaka K, Taira M, Shintani K, Wakasa K, Yamaki M. Residual monomers (TEGDMA and Bis-GMA) of a set visible-light-cured dental composite resin when immersed in water. J Oral Rehabil 1991; 18:353-362.

16. United States Food and Drug Administration (US FDA). Recommendations for chemistry data for indirect food additives petitions. USA, 1988.

17. Rueggeberg FA, Cole MA, Looney SW, Vickers A, Swift EJ. Comparison of manufacturer-recommended exposure durations with those determined using biaxial flexure strength and scraped composite thickness among a variety of light-curing units. J Esthet Restor Dent 2009;21:43-61.

18. Arrais CAG, Pontes FN, Santos LPS, Leite ER, Giannini M. Degree of conversion of adhesive systems light-cured by LED and halogen light. Braz Dent J 2007;18:54-59.

19. Park YJ, Chae KH, Rawls HR. Development of a new photoinitiation system for dental light-cure composite resins. Dent Mater 1999;15:120-127.

20. Ferracane JL, Condon JR. Rate of elution of leachable components from composite. Dent Mater 1990;6:282-287. 